\title{
Prognostic impact of the atherogenic index of plasma in type 2 diabetes mellitus patients with acute coronary syndrome undergoing percutaneous coronary intervention
}

Xiaoteng Ma ${ }^{\dagger}$, Yan Sun ${ }^{\dagger}$, Yujing Cheng ${ }^{\dagger}$, Hua Shen, Fei Gao, Jing Qi, Lixia Yang, Zhijian Wang, Dongmei Shi, Yuyang Liu, Xiaoli Liu* (D) and Yujie Zhou*

\begin{abstract}
Background: The association of the atherogenic index of plasma (AIP), an emerging lipid index that can predict the risk for cardiovascular disease, with adverse outcomes in type 2 diabetes mellitus (T2DM) patients with acute coronary syndrome (ACS) undergoing percutaneous coronary intervention (PCI) has not been determined. Therefore, the aim of this study was to investigate whether the AIP could independently predict adverse cardiovascular events in T2DM patients with ACS undergoing PCl.

Methods: This study was a retrospective analysis of a single-centre prospective registry involving 826 consecutive T2DM patients who underwent primary or elective PCI for ACS from June 2016 to November 2017. This study ultimately included 798 patients (age, $61 \pm 10$ years; male, 72.7\%). The AIP was calculated as the base 10 logarithm of the ratio of the plasma concentration of triglycerides to high-density lipoprotein-cholesterol (HDL-C). All the patients were divided into 4 groups based on the AIP quartiles. The primary endpoint was a composite of death from any cause, non-fatal spontaneous myocardial infarction (MI), non-fatal ischaemic stroke, and unplanned repeat revascularization. The key secondary endpoint was a composite of cardiovascular death, non-fatal Ml, and non-fatal ischaemic stroke.

(Continued on next page)
\end{abstract}

\footnotetext{
*Correspondence: liux19881@163.com; azzyj12@163.com

†Xiaoteng Ma, Yan Sun and Yujing Cheng contributed equally to this work. Department of Cardiology, Beijing Anzhen Hospital, Capital Medical University, Beijing Institute of Heart Lung and Blood Vessel Disease, Beijing Key Laboratory of Precision Medicine of Coronary Atherosclerotic Disease, Clinical Center for Coronary Heart Disease, Capital Medical University, Beijing 100029, China
}

C C The Author(s). 2020 Open Access This article is licensed under a Creative Commons Attribution 4.0 International License, which permits use, sharing, adaptation, distribution and reproduction in any medium or format, as long as you give appropriate credit to the original author(s) and the source, provide a link to the Creative Commons licence, and indicate if changes were made. The images or other third party material in this article are included in the article's Creative Commons licence, unless indicated otherwise in a credit line to the material. If material is not included in the article's Creative Commons licence and your intended use is not permitted by statutory regulation or exceeds the permitted use, you will need to obtain permission directly from the copyright holder. To view a copy of this licence, visit http://creativecommons.org/licenses/by/4.0/. The Creative Commons Public Domain Dedication waiver (http://creativecommons.org/publicdomain/zero/1.0/) applies to the data made available in this article, unless otherwise stated in a credit line to the data. 


\begin{abstract}
(Continued from previous page)
Results: During a median follow-up period of 927 days, 198 patients developed at least one event. An unadjusted Kaplan-Meier analysis showed that the incidence of the primary endpoint increased gradually with rising AIP quartiles (log-rank test, $P=0.001$ ). A multivariate Cox proportional hazards analysis revealed that compared with the lowest AIP quartile, the top AIP quartile was associated with significantly increased risk for the primary and key secondary endpoints (hazard ratio [HR]: 2.249, 95\% confidence interval [Cl]: 1.438 to 3.517, $P<0.001$; and HR: 2.571, 95\% Cl: 1.027 to $6.440, P=0.044$, respectively).
\end{abstract}

Conclusions: A higher AIP value on admission was independently and strongly associated with adverse cardiovascular events in T2DM patients with ACS undergoing PCl.

Keywords: Atherogenic index of plasma, Type 2 diabetes mellitus, Acute coronary syndrome, Percutaneous coronary intervention, Adverse cardiovascular events

\section{Background}

Type 2 diabetes mellitus (T2DM) has been established as an important risk factor for adverse outcomes in patients with acute coronary syndrome (ACS) [1-3]; this phenomenon may be due to the rapid development of atherosclerosis related to T2DM [4-7]. T2DM patients with ACS remain at a very high residual risk of adverse cardiovascular events and mortality despite receiving percutaneous coronary intervention (PCI) and guideline-recommended first-line medication therapies [8-11]. Therefore, further risk assessment of such patients may help better determine prognosis and guide better medical management.

Dyslipidaemia is a common comorbidity in T2DM and ACS patients. The dyslipidaemic pattern in diabetic patients [mainly characterized by high levels of fasting and postprandial triglyceride-rich lipoproteins, reduced highdensity lipoprotein-cholesterol (HDL-C), normal or slightly elevated low-density lipoprotein-cholesterol (LDL-C), and increased number of small dense LDL-C particles] is somewhat different from that in nondiabetic patients [12]. The atherogenic index of plasma (AIP), readily calculated from the lipid profile as $\log _{10}$ (triglycerides/HDL-C), is considered an alternative and simple marker of plasma atherogenicity based on an observed significant, positive relationship between the AIP and cholesterol esterification rates in apoB-lipoproteindepleted plasma (FER (HDL)), very-low-density lipoprotein particle size, remnant lipoprotein particle cholesterol, and LDL density and the inverse correlation of the AIP with particle sizes of HDL and LDL [13-19]. As a consequence, AIP can be presumed to reflect the lipid characteristics of diabetic patients. Recently, AIP has been demonstrated to be associated with cardiovascular outcomes in the general population and different patient groups [20-31]. However, the prognostic impact of AIP on admission among T2DM patients with ACS undergoing PCI has not been exclusively studied. AIP on admission is hypothesized to be an independent predictor of adverse cardiovascular events in T2DM and ACS patients who underwent PCI.

\section{Methods}

\section{Study population}

This study was a retrospective analysis of a single-centre prospective registry involving 826 consecutive T2DM patients who underwent primary or elective PCI for ACS from June 2016 to November 2017 [32]. The inclusion criteria included diagnosis of ACS according to the American College of Cardiology/American Heart Association guidelines $[33,34]$ and T2DM according to American Diabetes Association guidelines [35], as well as treatment with primary or elective PCI. For the purpose of this study, patients with prior coronary artery bypass grafting, left ventricular ejection fraction (LVEF) $<30 \%$, cardiogenic shock, and renal failure requiring haemodialysis were excluded. Cardiogenic shock was defined as a condition in which systolic blood pressure remains below $90 \mathrm{mmHg}$ despite adequate blood perfusion, accompanied by clinical signs or laboratory parameters suggestive of hypoperfusion, or in which systolic blood pressure is maintained above $90 \mathrm{mmHg}$ with positive inotropic agents and/or mechanical circulatory support. Renal failure requiring haemodialysis was defined as having a creatinine clearance of less than $15 \mathrm{ml} /$ min or being on haemodialysis. Three patients were also excluded due to lack of follow-up data. A total of 798 patients were eventually included in the present analysis. None of the patients received medications specifically designed to raise HDL-C or lower triglyceride levels, such as niacin, fibrates, and omega- 3 fatty acids, before admission or at discharge. For statins, all patients were given either atorvastatin or rosuvastatin, and the vast majority took regular doses of atorvastatin or rosuvastatin (i.e., atorvastatin $20 \mathrm{mg}$ or rosuvastatin $10 \mathrm{mg}$ ).

\section{Measurement}

The fasting plasma glucose (FPG), total cholesterol, HDL-C, and triglyceride levels after admission were measured in the central laboratory of Beijing Anzhen Hospital. The Friedewald equation was used to calculate the LDL-C level. Dyslipidaemia was defined as fasting 
total cholesterol $>5.17 \mathrm{mmol} / \mathrm{L}, \quad \mathrm{LDL}-\mathrm{C}>3.36 \mathrm{mmol} / \mathrm{L}$, triglycerides $>1.69 \mathrm{mmol} / \mathrm{L}, \mathrm{HDL}-\mathrm{C}<1.03 \mathrm{mmol} / \mathrm{L}$, and/ or chronic use of lipid-lowering drugs. The AIP was calculated as the $\log _{10}$ of the ratio of the plasma concentration of triglycerides to HDL-C [13]. Moreover, demographics, medical history and medication history data for all patients were collected using standard questionnaires.

\section{Follow-up and endpoints}

The follow-up time points were 1 month and every 6 months after hospital discharge. Trained personnel who were not aware of patients' baseline data obtained information about adverse events via telephone contact with patients or their family members using standardized questionnaires; adverse events were identified by carefully reviewing the corresponding medical records. The primary endpoint was a composite of death from any cause, non-fatal spontaneous myocardial infarction (MI), non-fatal ischaemic stroke, and unplanned repeat revascularization. The key secondary endpoint was a composite of cardiovascular death, non-fatal MI, and non-fatal ischaemic stroke. Adverse events were defined in accordance with previous publications [32, 36]. The follow-up period ended in November 2019.

\section{Statistical analysis}

Power analyses to assess the required sample size were not performed since the present study is a retrospective analysis of a single-centre prospective registry, and currently, there is no literature on longitudinal analyses of the prognostic value of the AIP in a similar study population; therefore, adequate estimation of power is not possible.

All patients were stratified into 4 groups (Q1 [AIP $\leq 0.0147$ ], Q2 [0.0147 < AIP $\leq 0.1850]$, Q3 [0.1850< AIP $\leq 0.3517$ ] and Q4 [AIP >0.3517]) according to the AIP quartiles. Categorical variables were expressed as frequencies and percentages. Chi-squared test or Fisher's exact test was applied to determine the statistical significance of the differences in categorical variables between groups. Continuous variables with parametric distributions were expressed as the means \pm standard deviations, and those with non-parametric distributions were expressed as medians and interquartile ranges. Unpaired $\mathrm{t}$-test or Mann-Whitney $U$ test and analysis of variance or Kruskal-Wallis $\mathrm{H}$ test were used to estimate the statistical significance of differences in continuous variables between groups. Kaplan-Meier curves and Cox proportional hazards models were used to conduct survival analyses of the primary and key secondary endpoints. The log-rank test was used to evaluate the differences between Kaplan-Meier estimates. Cox proportional hazards analysis results are presented using hazard ratios
(HRs) with 95\% confidence intervals (CIs). Variables of statistical significance in the univariate analysis as well as clinical importance were included in the multivariate Cox proportional hazards model. In the multivariate model for the primary endpoint, the following confounding variables were chosen: age (continuous, per 1-year increase), body mass index (BMI) (continuous, per 1unit increase), hypertension (with or without), previous MI (with or without), past PCI (with or without), peripheral artery disease (with or without), cardiac failure (with or without), LVEF (continuous, per 1\% increase), serum creatinine (continuous, per 1-unit increase), LDL-C (continuous, per 1-unit increase), FPG (continuous, per 1-unit increase), clinical presentation (unstable angina pectoris as reference), coronary artery disease (CAD) severity (one-vessel disease as reference), lesions $>20 \mathrm{~mm}$ long (with or without), restenotic lesions (with or without), use of drug-coated balloon (yes or no), complete revascularization (yes or no), and use of insulin at discharge (yes or no). In the multivariate model for the key secondary endpoint, the following confounding variables were chosen: age (continuous, per 1-year increase), BMI (continuous, per 1-unit increase), hypertension (with or without), past PCI (with or without), peripheral artery disease (with or without), cardiac failure (with or without), LVEF (continuous, per 1\% increase), serum creatinine (continuous, per 1-unit increase), LDL-C (continuous, per 1-unit increase), glycated haemoglobin (continuous, per 1\% increase), clinical presentation (unstable angina pectoris as reference), CAD severity (onevessel disease as reference), lesions $>20 \mathrm{~mm}$ long (with or without), complete revascularization (yes or no), and use of angiotensin-converting enzyme inhibitors/angiotensin II receptor blockers (ACEIs/ARBs) at discharge (yes or no). Interaction was tested with a likelihood ratio test, and the proportional hazard assumption was tested by demonstrating no importance of variables multiplied by time as time-dependent variables. Post hoc subgroup analyses stratified by age ( $<60$ versus $\geq 60$ years), sex (female versus male), BMI ( $<28$ versus $\left.\geq 28 \mathrm{~kg} / \mathrm{m}^{2}\right)$, LDL-C $(\leq 1.8$ versus $>1.8 \mathrm{mmol} / \mathrm{L}$ ), hypertension (yes versus no), and clinical presentation (non-ST versus ST segment elevation ACS) were used to determine the consistency of the prognostic impacts of the AIP as a continuous variable for the primary endpoint. SPSS version 24.0 (IBM Corp., Armonk, New York, US) was used for analyses. A 2 -sided $P$-value $<0.05$ was considered significant.

\section{Results}

A total of 798 T2DM patients with ACS undergoing PCI were included in the present analysis. The mean age of these patients was $61 \pm 10$ years, and male patients accounted for $72.7 \%$. The baseline clinical and laboratory 
characteristics of the study population according to the AIP quartiles are listed in Table 1. Patients with higher AIP values tended to be younger, were predominantly male, had higher rates of current smoking and dyslipidaemia, and had lower rates of never smoking and diagnosis with unstable angina pectoris. Patients with higher AIP values were more likely than patients with lower AIP values to have higher levels of BMI, serum creatinine, uric acid, total cholesterol, LDL-C, triglycerides, and FPG but lower levels of HDL-C. The use of medications, angiographic findings, and procedural results of the study population according to the AIP quartiles are summarized in Table 2. With the exception of $\beta$ blockers, medications before admission did not differ across the different AIP groups. With the exception of P2Y12 inhibitors, ACEIs/ARBs, and oral antidiabetic agents, medications at discharge were similar among the different AIP groups. Patients who had higher AIP values were more likely to receive ACEIs/ARBs at discharge. The proportions of left main/three-vessel disease and two-vessel disease were different among the different AIP groups. Patients with higher AIP values tended to have a higher rate of chronic total occlusions and a lower rate of heavy calcification lesions. The proportions of left circumflex artery and right coronary artery interventions were different among the different AIP groups. Patients with higher AIP values tended to have a lower rate of complete revascularization.

Patients were followed up for a median of 927 days (interquartile range, 774 to 1109 days). During the period, 198 patients developed at least one adverse cardiovascular event, which was found in 33 (16.6\%) patients from the Q1 group, 45 (22.5\%) from the Q2 group, 54 (27.0\%) from the Q3 group, and 66 (33.2\%) from the Q4 group. Of the 198 patients with at least one adverse cardiovascular event, 20 died (18 died from cardiovascular causes, and 2 died from non-cardiovascular causes), 24 developed non-fatal spontaneous MI, 17 developed non-fatal ischaemic stroke, and 180 underwent unplanned repeat revascularization; among these patients, 33 had two, 2 had three, and 2 had four adverse cardiovascular events.

Kaplan-Meier analyses revealed a significantly higher incidence of the primary endpoint (log-rank test, $P=$ 0.001; Fig. 1a) and a marginally but non-significantly higher incidence of the key secondary endpoint (logrank test, $P=0.114$; Fig. $1 \mathrm{~b}$ ) in patients with higher AIP values. The difference in the incidence of the primary endpoint was due mainly to an increase in unplanned repeat revascularization (log-rank test, $P=0.005$; Fig. 1f) across the AIP quartiles. However, the incidence of death from any cause (log-rank test, $P=0.168$; Fig. 1c), cardiovascular death (log-rank test, $P=0.459$ ), non-fatal ischaemic stroke (log-rank test, $P=0.167$; Fig. $1 d$ ), and non-fatal spontaneous MI (log-rank test, $P=0.636$; Fig. 1e) did not differ among the AIP quartiles at follow-up.

Table 3 shows univariate and multivariate Cox proportional hazards analyses for the primary endpoint at follow-up. A multivariate Cox proportional hazards analysis, with Q1 as a reference, showed that the AIP for Q4 had a significantly increased HR $(2.249,95 \%$ CI 1.438-3.517) for the incidence of the primary endpoint. Moreover, the AIP used as a continuous variable was independently predictive of the primary endpoint $(\mathrm{HR}$, 2.684; 95\% CI, $1.585-4.546 ; P<0.001)$. Table 4 shows univariate and multivariate Cox proportional hazards analyses for the key secondary endpoint at follow-up. A multivariate Cox proportional hazards analysis, with Q1 as a reference, showed that the AIP for Q4 had a significantly increased HR $(2.571,95 \%$ CI 1.027-6.440) for the incidence of the key secondary endpoint. Moreover, the AIP used as a continuous variable was independently predictive of the key secondary endpoint (HR, 3.160; 95\% CI, 1.040-9.600; $P=0.042$ ).

The predictive impacts of the AIP as a continuous variable for the primary endpoint were further assessed in different subgroups of the study population. Increased AIP value (per 1-unit) was consistently associated with the primary endpoint in different subgroups, including age $<60$ versus $\geq 60$ years, female versus male sex, BMI $<28$ versus $\geq 28 \mathrm{~kg} / \mathrm{m}^{2}, \mathrm{LDL}-\mathrm{C} \leq 1.8$ versus $>1.8 \mathrm{mmol} / \mathrm{L}$, with versus without hypertension, and non-ST versus ST segment elevation ACS (Fig. 2).

\section{Discussion}

The main findings of this study were as follows: (1) patients with higher AIP values had a significantly higher probability of adverse cardiovascular events by the logrank test, and (2) multivariate Cox proportional hazards analyses showed that the AIP was independently and strongly associated with the primary and key secondary endpoints in T2DM and ACS patients who underwent PCI, suggesting that the AIP might have a potential role in early risk stratification of such patients.

Dyslipidaemia plays a crucial role in the pathogenesis and progression of coronary atherosclerosis [37]. Diabetic patients are more likely to develop coronary atherosclerosis than non-diabetic patients, which may be significantly associated with so-called diabetic dyslipidaemia, which consists of elevated plasma concentrations of triglyceride-rich lipoproteins and small dense LDL-C particles and low levels of HDL-C. The different components of diabetic dyslipidaemia are not isolated abnormalities but are closely linked to each other metabolically [12]. Triglycerides and HDL-C are two lipid parameters measured routinely in clinical practice; however, neither is a consistently good proxy for plasma atherogenicity. The AIP, a novel lipid index defined as 
Table 1 Baseline clinical and laboratory characteristics of the study population according to the AIP quartiles

\begin{tabular}{|c|c|c|c|c|c|c|c|c|c|c|c|}
\hline \multirow[t]{2}{*}{ Variable } & \multirow{2}{*}{$\begin{array}{l}\text { Q1 } \\
n=199\end{array}$} & \multirow{2}{*}{$\begin{array}{l}\text { Q2 } \\
n=200\end{array}$} & \multirow{2}{*}{$\begin{array}{l}\text { Q3 } \\
n=200\end{array}$} & \multirow{2}{*}{$\begin{array}{l}\text { Q4 } \\
n=199\end{array}$} & \multicolumn{7}{|l|}{$P$ value } \\
\hline & & & & & Overall & $\begin{array}{l}\text { Q2 vs. } \\
\text { Q1 * }\end{array}$ & $\begin{array}{l}\text { Q3 vs. } \\
\text { Q1 * }\end{array}$ & $\begin{array}{l}\text { Q3 vs. } \\
\text { Q2 * }\end{array}$ & $\begin{array}{l}\text { Q4 vs. } \\
\text { Q1 * }\end{array}$ & $\begin{array}{l}\text { Q4 vs. } \\
\text { Q2 * }\end{array}$ & $\begin{array}{l}\text { Q4 vs. } \\
\text { Q3 * }\end{array}$ \\
\hline \multicolumn{12}{|l|}{ Demographics } \\
\hline Age (years) & $63 \pm 8$ & $63 \pm 10$ & $61 \pm 9$ & $58 \pm 12$ & $<0.001$ & 0.750 & 0.051 & 0.498 & $<0.001$ & $<0.001$ & 0.007 \\
\hline Male sex, n (\%) & $125(62.8)$ & $146(73.0)$ & $153(76.5)$ & $156(78.4)$ & 0.002 & 0.029 & 0.003 & 0.420 & 0.001 & 0.209 & 0.651 \\
\hline \multicolumn{12}{|c|}{ Clinical values (on admission) } \\
\hline BMI $\left(\mathrm{kg} / \mathrm{m}^{2}\right)$ & $25.3 \pm 3.1$ & $25.4 \pm 2.8$ & $26.1 \pm 3.1$ & $27.0 \pm 3.5$ & $<0.001$ & 0.997 & 0.081 & 0.129 & $<0.001$ & $<0.001$ & 0.028 \\
\hline $\mathrm{SBP}(\mathrm{mm} \mathrm{Hg})$ & $133 \pm 18$ & $133 \pm 17$ & $130 \pm 16$ & $131 \pm 16$ & 0.116 & - & - & - & - & - & - \\
\hline DBP $(\mathrm{mm} \mathrm{Hg})$ & $75 \pm 11$ & $76 \pm 10$ & $75 \pm 10$ & $77 \pm 11$ & 0.203 & - & - & - & - & - & - \\
\hline
\end{tabular}

\section{Risk factors}

\section{Smoking status}

Current smoking,

$\mathrm{n}(\%)$

Former smoking,

$\mathrm{n}(\%)$

Never smoking

$\mathrm{n}(\%)$

Chronically daily

drinking, n (\%)

Family history of

CHD, n (\%)

Hypertension,

n (\%)

Dyslipidaemia, n (\%)

Previous MI, n (\%)

Past PCl, n (\%)

Previous ischemic

stroke or TIA

$\mathrm{n}(\%)$

PAD, n (\%)
Cardiac failure, n (\%)

LVEF (\%)

\section{Clinical presentation}

$$
\text { UAP, n (\%) }
$$

NSTEMI, n (\%)

STEMI, n (\%)

Laboratory measurements (fasting state)

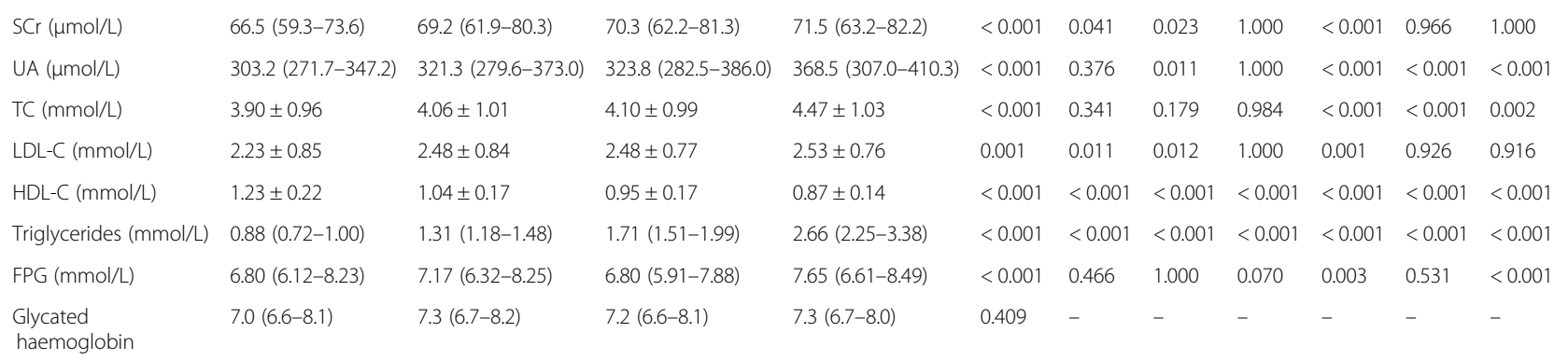

(\%)

AIP

$\begin{array}{lll}77(38.5) & 76(38.0) & 111(55.8) \\ 33(16.5) & 38(19.0) & 26(13.1) \\ 90(45.0) & 86(43.0) & 62(31.2) \\ 18(9.0) & 26(13.0) & 21(10.6) \\ 60(30.0) & 69(34.5) & 56(28.1) \\ 137(68.5) & 141(70.5) & 130(65.3) \\ 174(87.0) & 192(96.0) & 195(98.0) \\ 43(21.5) & 40(20.0) & 51(25.6) \\ 50(25.0) & 50(25.0) & 44(22.1) \\ 13(6.5) & 17(8.5) & 8(4.0) \\ 64(60-68) & 65(60-68) & 65(59-68) \\ 29(14.5) & 31(15.5) & 33(16.6) \\ 13(6.5) & 23(11.5) & 19(9.5) \\ & & \end{array}$

$\begin{array}{lllllll}<0.001 & 0.079 & 0.098 & 0.918 & <0.001 & 0.001 & <0.001\end{array}$

0.455

$\begin{array}{lllllll}<0.001 & 0.099 & 0.040 & 0.687 & <0.001 & 0.004 & 0.014\end{array}$

0.234

0.386

0.715

$<0.001<0.001<0.001 \quad 0.001<0.001<0.001 \quad 0.245$

0.301

0.891

0.338

0.853

0.156

0.963

$153(76.5) \quad 150(75.0) \quad 153(76.9)$

$\begin{array}{lllllll}0.033 & 0.016 & 0.006 & 0.726 & 0.020 & 0.928 & 0.660\end{array}$

$28(14.0)$

$28(14.5)$

25 (12.6)

21 (10.6)

0.493

0.088

\section{-}


Table 2 Use of medications, agiographic findings, and procedural results of the study population according to the AIP quartiles

\begin{tabular}{|c|c|c|c|c|c|c|c|c|c|c|c|}
\hline \multirow[t]{2}{*}{ Variable } & \multirow{2}{*}{$\begin{array}{l}\text { Q1 } \\
n=199\end{array}$} & \multirow{2}{*}{$\begin{array}{l}\text { Q2 } \\
n=200\end{array}$} & \multirow{2}{*}{$\begin{array}{l}\mathrm{Q} 3 \\
n=200\end{array}$} & \multirow{2}{*}{$\begin{array}{l}\text { Q4 } \\
n=199\end{array}$} & \multicolumn{7}{|l|}{$P$ value } \\
\hline & & & & & Overall & $\begin{array}{l}\text { Q2 vs. } \\
\text { Q1 * }\end{array}$ & $\begin{array}{l}\text { Q3 vs. } \\
\text { Q1 * }\end{array}$ & $\begin{array}{l}\text { Q3 vs. } \\
\text { Q2 * }\end{array}$ & $\begin{array}{l}\text { Q4 vs. } \\
\text { Q1 * }\end{array}$ & $\begin{array}{l}\text { Q4 vs. } \\
\text { Q2 * }\end{array}$ & $\begin{array}{l}\text { Q4 vs. } \\
\text { Q3 * }\end{array}$ \\
\hline \multicolumn{12}{|c|}{ Medications before admission } \\
\hline Aspirin, n (\%) & $145(72.9)$ & $149(74.5)$ & $154(77.0)$ & $146(73.4)$ & 0.784 & - & - & - & - & - & - \\
\hline $\begin{array}{l}\text { P2Y12 inhibitors, } \\
\text { n (\%) }\end{array}$ & $81(40.7)$ & $81(40.5)$ & $74(37.0)$ & $80(40.2)$ & 0.858 & - & - & - & - & - & - \\
\hline Statins, n (\%) & $150(75.4)$ & $143(71.5)$ & $155(77.5)$ & $142(71.4)$ & 0.418 & - & - & - & - & - & - \\
\hline ACEIs/ARBs, n (\%) & $55(27.6)$ & $65(32.5)$ & $72(36.0)$ & $69(34.7)$ & 0.300 & - & - & - & - & - & - \\
\hline$\beta$-blockers, n (\%) & $70(35.2)$ & $79(39.5)$ & $93(46.5)$ & $63(31.7)$ & 0.016 & 0.372 & 0.021 & 0.157 & 0.457 & 0.102 & 0.002 \\
\hline Insulin, n (\%) & $75(37.7)$ & $73(36.5)$ & $79(39.5)$ & $63(31.7)$ & 0.406 & - & - & - & - & - & - \\
\hline $\begin{array}{l}\text { Oral antidiabetic } \\
\text { agents, } \mathrm{n}(\%)\end{array}$ & $89(44.7)$ & $98(49.0)$ & $110(55.0)$ & $90(45.2)$ & 0.145 & - & - & - & - & - & - \\
\hline \multicolumn{12}{|c|}{ Intraoperative anticoagulants } \\
\hline $\begin{array}{l}\text { Unfractionated } \\
\text { heparin, n (\%) }\end{array}$ & $168(84.4)$ & $170(85.0)$ & $154(77.0)$ & $156(78.4)$ & 0.086 & - & - & - & - & - & - \\
\hline LMWH, n (\%) & $6(3.0)$ & $7(3.5)$ & $16(8.0)$ & $10(5.0)$ & 0.089 & - & - & - & - & - & - \\
\hline Bivalirudin, n (\%) & $25(12.6)$ & $23(11.5)$ & $30(15.0)$ & $33(16.6)$ & 0.448 & - & - & - & - & - & - \\
\hline \multicolumn{12}{|c|}{ Perioperative medications } \\
\hline Aspirin, n (\%) & $196(98.5)$ & $198(99.0)$ & $200(100.0)$ & $196(98.5)$ & 0.308 & - & - & - & - & - & - \\
\hline $\begin{array}{l}\text { P2Y12 inhibitors, } \\
\text { n (\%) }\end{array}$ & $199(100.0)$ & $200(100.0)$ & $200(100.0)$ & $199(100.0)$ & - & - & - & - & - & - & - \\
\hline $\begin{array}{l}\text { GP IIb/Illa receptor } \\
\text { antagonist, n (\%) }\end{array}$ & $29(14.6)$ & $38(19.0)$ & $45(22.5)$ & $37(18.6)$ & 0.246 & - & - & - & - & - & - \\
\hline \multicolumn{12}{|c|}{ Medications at discharge } \\
\hline Aspirin, n (\%) & $196(98.5)$ & $198(99.0)$ & $200(100.0)$ & $196(98.5)$ & 0.308 & - & - & - & - & - & - \\
\hline Cilostazol, n (\%) & $3(1.5)$ & $2(1.0)$ & $1(0.5)$ & $4(2.0)$ & 0.473 & - & - & - & - & - & - \\
\hline Clopidogrel, n (\%) & $174(87.4)$ & $183(91.5)$ & $178(89.0)$ & $190(95.5)$ & 0.031 & 0.186 & 0.628 & 0.399 & 0.004 & 0.108 & 0.016 \\
\hline Ticagrelor, n (\%) & $25(12.6)$ & $17(8.5)$ & $22(11.0)$ & $9(4.5)$ & 0.031 & 0.186 & 0.628 & 0.399 & 0.004 & 0.108 & 0.016 \\
\hline Statins, n (\%) & $199(100.0)$ & $200(100.0)$ & $200(100.0)$ & $199(100.0)$ & - & - & - & - & - & - & - \\
\hline ACEIs/ARBs, n (\%) & $81(40.7)$ & $93(46.5)$ & $105(52.5)$ & $121(60.8)$ & 0.001 & 0.243 & 0.018 & 0.230 & $<0.001$ & 0.004 & 0.094 \\
\hline$\beta$-blockers, n (\%) & $138(69.3)$ & $147(73.5)$ & $155(77.5)$ & $136(68.3)$ & 0.155 & - & - & - & - & - & - \\
\hline Insulin, n (\%) & $65(32.7)$ & $76(38.0)$ & $72(36.0)$ & 57 (28.6) & 0.213 & - & - & - & - & - & - \\
\hline $\begin{array}{l}\text { Oral antidiabetic } \\
\text { agents, } \mathrm{n}(\%)\end{array}$ & $87(43.7)$ & $120(60.0)$ & $119(59.5)$ & $105(52.8)$ & 0.003 & 0.001 & 0.002 & 0.919 & 0.071 & 0.145 & 0.175 \\
\hline \multicolumn{12}{|l|}{ Angiographic findings } \\
\hline $\begin{array}{l}\text { One-vessel disease, } \\
\mathrm{n}(\%)\end{array}$ & $22(11.1)$ & $15(7.5)$ & $18(9.0)$ & $25(12.6)$ & 0.347 & - & - & - & - & - & - \\
\hline $\begin{array}{l}\text { Two-vessel disease, } \\
\text { n (\%) }\end{array}$ & $68(34.2)$ & $41(20.5)$ & $42(21.0)$ & $46(23.1)$ & 0.004 & 0.002 & 0.003 & 0.902 & 0.015 & 0.527 & 0.610 \\
\hline $\begin{array}{l}\text { LM/three-vessel } \\
\text { disease, } n(\%)\end{array}$ & $109(54.8)$ & $144(72.0)$ & $140(70.0)$ & $128(64.3)$ & 0.001 & $<0.001$ & 0.002 & 0.659 & 0.052 & 0.100 & 0.227 \\
\hline $\begin{array}{l}\text { Proximal LAD } \\
\text { stenosis, } \mathrm{n}(\%)\end{array}$ & $94(47.2)$ & $110(55.0)$ & $97(48.5)$ & $100(50.3)$ & 0.428 & - & - & - & - & - & - \\
\hline $\begin{array}{l}\text { Restenotic lesions, } \\
\mathrm{n}(\%)\end{array}$ & $26(13.1)$ & $26(13.0)$ & $30(15.0)$ & 29 (14.6) & 0.913 & - & - & - & - & - & - \\
\hline $\begin{array}{l}\text { Trifurcation or } \\
\text { bifurcation lesions, } \\
\mathrm{n}(\%)\end{array}$ & 155 (77.9) & $162(81.0)$ & $151(75.5)$ & $148(74.4)$ & 0.403 & - & - & - & - & - & - \\
\hline Chronic total & $36(18.1)$ & $46(23.0)$ & $44(22.0)$ & 57 (28.6) & 0.093 & - & - & - & - & - & - \\
\hline
\end{tabular}


Table 2 Use of medications, agiographic findings, and procedural results of the study population according to the AIP quartiles (Continued)

\begin{tabular}{|c|c|c|c|c|c|c|c|c|c|c|c|}
\hline \multirow[t]{2}{*}{ Variable } & \multirow{2}{*}{$\begin{array}{l}\text { Q1 } \\
n=199\end{array}$} & \multirow{2}{*}{$\begin{array}{l}\text { Q2 } \\
n=200\end{array}$} & \multirow{2}{*}{$\begin{array}{l}\text { Q3 } \\
n=200\end{array}$} & \multirow{2}{*}{$\begin{array}{l}\text { Q4 } \\
n=199\end{array}$} & \multicolumn{7}{|l|}{$P$ value } \\
\hline & & & & & Overall & $\begin{array}{l}\text { Q2 vs. } \\
\text { Q1 * }\end{array}$ & $\begin{array}{l}\text { Q3 vs. } \\
\text { Q1 * }\end{array}$ & $\begin{array}{l}\text { Q3 vs. } \\
\text { Q2* }\end{array}$ & $\begin{array}{l}\text { Q4 vs. } \\
\text { Q1 * }\end{array}$ & $\begin{array}{l}\text { Q4 vs. } \\
\text { Q2* }\end{array}$ & $\begin{array}{l}\text { Q4 vs. } \\
\text { Q3 * }\end{array}$ \\
\hline \multicolumn{12}{|l|}{ occlusions, n (\%) } \\
\hline $\begin{array}{l}\text { Thrombus lesions, } \\
\mathrm{n}(\%)\end{array}$ & $7(3.5)$ & $14(7.0)$ & $12(6.0)$ & $12(6.0)$ & 0.478 & - & - & - & - & - & - \\
\hline $\begin{array}{l}\text { Heavy calcification } \\
\text { lesions, n (\%) }\end{array}$ & $75(37.7)$ & $69(34.5)$ & $73(36.5)$ & $48(24.1)$ & 0.016 & 0.507 & 0.806 & 0.676 & 0.003 & 0.023 & 0.007 \\
\hline $\begin{array}{l}\text { Lesions > } 20 \mathrm{~mm} \\
\text { long, } \mathrm{n}(\%)\end{array}$ & $108(54.3)$ & $112(56.0)$ & $122(61.0)$ & $117(58.8)$ & 0.537 & - & - & - & - & - & - \\
\hline \multicolumn{12}{|l|}{ Procedural results } \\
\hline \multicolumn{12}{|c|}{ Target vessel territory } \\
\hline LM, n (\%) & $13(6.5)$ & $16(8.0)$ & $9(4.5)$ & $18(9.0)$ & 0.313 & - & - & - & - & - & - \\
\hline LAD, n (\%) & $104(52.3)$ & $97(48.5)$ & $100(50.0)$ & $99(49.7)$ & 0.899 & - & - & - & - & - & - \\
\hline LCX, n (\%) & $64(32.2)$ & $69(34.5)$ & $42(21.0)$ & $48(24.1)$ & 0.007 & 0.620 & 0.012 & 0.003 & 0.075 & 0.023 & 0.456 \\
\hline RCA, n (\%) & $69(34.7)$ & $82(41.0)$ & $100(50.0)$ & $74(37.2)$ & 0.011 & 0.193 & 0.002 & 0.071 & 0.601 & 0.435 & 0.010 \\
\hline DES use, n (\%) & $174(87.4)$ & $172(86.0)$ & $161(80.5)$ & $159(79.9)$ & 0.097 & - & - & - & - & - & - \\
\hline BRS use, n (\%) & $6(3.0)$ & $7(3.5)$ & $8(4.0)$ & $11(5.5)$ & 0.607 & - & - & - & - & - & - \\
\hline DCB use, n (\%) & $12(6.0)$ & $11(5.5)$ & $19(9.5)$ & $14(7.0)$ & 0.409 & - & - & - & - & - & - \\
\hline $\begin{array}{l}\text { Complete } \\
\text { revascularization, } \\
\mathrm{n}(\%)\end{array}$ & $136(68.3)$ & $115(57.5)$ & $110(55.0)$ & $107(53.8)$ & 0.012 & 0.025 & 0.006 & 0.614 & 0.003 & 0.453 & 0.805 \\
\hline
\end{tabular}

${ }^{*} P<0.0083$ is considered statistically significant for post hoc multiple comparisons of categorical variables between groups

$A I P$ Indicates atherogenic index of plasma; $A C E I s$ Angiotensin converting enzyme inhibitors; $A R B s$ Angiotensin II receptor blockers; $L M$ Left-main artery; $L A D$ Left anterior descending artery; $L C X$ Left circumflex artery; RCA Right coronary artery; DES Drug-eluting stent; BRS Bioresorbable scaffold; $D C B$ Drug-coated balloon

$\log _{10}$ (triglycerides/HDL-C), has been demonstrated to be closely correlated with FER (HDL) and lipoprotein particle size, both of which are directly involved in the pathogenesis and development of atherosclerosis; thus, the AIP is regarded as an excellent indicator of atherosclerosis and can offer a benefit to identify the risk of cardiovascular disease [38].

Multiple cross-sectional studies reported that the AIP was a strong predictor of CAD independent of diabetes [26, 27, 29]. Notably, the Indian Atherosclerosis Research Study revealed that the addition of the AIP and family history to traditional risk factors improved risk discrimination (C-index: from 0.864 to 0.873 ) in Asian Indians with CAD [22]. Intriguingly, Frohlich $J$ et al. found that the AIP was an independent predictor of angiographically defined CAD only when FER (HDL) was omitted from multivariate analysis, which may be due to a clear internal correlation between the AIP and FER (HDL) [20]. Moreover, Nam JS et al. found that there is a significant correlation between the AIP and the progression of coronary artery calcification measured by using multidetector computed tomography in subjects without cardiovascular disease [31]. Furthermore, in a prospective cohort study including 2676 middle-aged adults followed for 7.8 years, researchers demonstrated that the top quartiles of the AIP predicted significantly age-adjusted incident CAD in both sexes, more strongly in women, after adjustment for C-reactive protein and traditional risk factors [21].

The AIP has been demonstrated to be associated with mortality in elderly patients and dialysis patients. Edwards MK et al. analysed data from the 1999-2006 National Health and Nutrition Examination Survey with follow-up through 2011 to find that the AIP was positively and independently associated with mortality risk and predicted mortality risk better than individual cholesterol risk factors among an older adult population [23]. Bendzala $\mathrm{M}$ et al. also found that the AIP was positively associated with the risk of all-cause death in elderly women with hypertension [24]. However, a Korean nationwide prospective cohort study including 1174 incident dialysis patients showed that the AIP had a nonlinear relationship with survival; both the highest and the lowest AIP quintiles were independently associated with all-cause mortality, showing a U-shaped association [25].

The predictive value of the AIP has also been explored in ACS patients. Cai $G$ et al. retrospectively enrolled 1478 very young participants ( $\leq 35$ years of age) undergoing coronary angiography and divided them into two groups: the ACS group $(n=1058)$ and the non-CAD group $(n=419)$. They found that the AIP was 


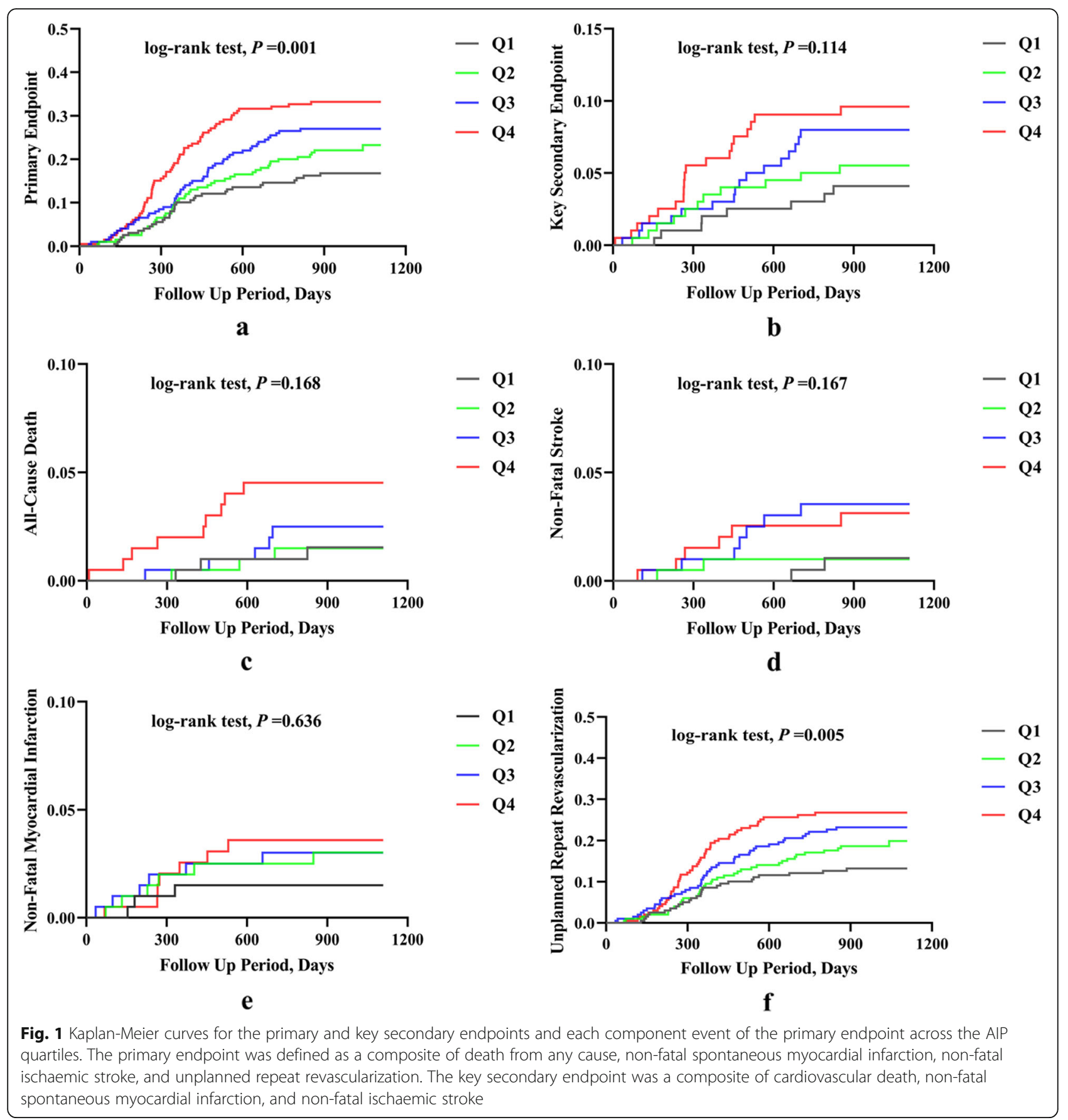

independently associated with the presence and severity of ACS in a sex-dependent manner and that the prevalence of ACS, acute MI, and unstable angina pectoris and the Gensini score (a scoring system for evaluating CAD severity) were elevated as AIP quartiles increased [28]. Qin Z et al. retrospectively enrolled 2356 T2DM patients who underwent PCI and followed them for 4 years. They found that the AIP was an independent predictor of major cardiovascular and cerebrovascular adverse events, including cardiac death, MI, repeated revascularization, and stroke, regardless of clinical presentation [30].

The AIP was reported to be positively correlated with serum malondialdehyde levels in menopausal women with cardiovascular disease [39], and malondialdehyde can reflect the status of oxidative stress, which is significantly associated with coronary atherosclerosis [40]. The AIP was found to be associated with epicardial adipose tissue measured by using transthoracic echocardiography or electrocardiogram-gated multidetector computed 
Table 3 Relationship between the incidence of the primary endpoint and the AIP expressed as a categorical variable

\begin{tabular}{|c|c|c|c|c|}
\hline Variables & $\begin{array}{l}\text { Univariate analysis } \\
\text { HR }(95 \% \mathrm{CI})\end{array}$ & $P$-value & $\begin{array}{l}\text { Multivariate analysis } \\
\text { HR }(95 \% \mathrm{Cl})\end{array}$ & $P$-value \\
\hline \multicolumn{5}{|l|}{ AIP quartiles } \\
\hline Q1 & Reference & & Reference & \\
\hline Q2 & $1.376(0.878-2.156)$ & 0.164 & $1.167(0.733-1.857)$ & 0.516 \\
\hline Q3 & $1.710(1.109-2.636)$ & 0.015 & $1.570(0.995-2.478)$ & 0.053 \\
\hline Q4 & $2.265(1.491-3.440)$ & $<0.001$ & $2.249(1.438-3.517)$ & $<0.001$ \\
\hline Age & 1.005 (0.991-1.019) & 0.472 & $0.996(0.980-1.012)$ & 0.642 \\
\hline BMl & $0.959(0.916-1.005)$ & 0.078 & $0.922(0.876-0.970)$ & 0.002 \\
\hline Hypertension & 1.068 (0.789-1.447) & 0.669 & $1.241(0.890-1.729)$ & 0.203 \\
\hline Previous Ml & $1.492(1.095-2.033)$ & 0.011 & $0.781(0.532-1.145)$ & 0.205 \\
\hline Past PCl & $1.723(1.285-2.310)$ & $<0.001$ & $1.263(0.734-2.080)$ & 0.425 \\
\hline PAD & $2.511(1.836-3.435)$ & $<0.001$ & $1.717(1.192-2.473)$ & 0.004 \\
\hline Cardiac failure & 1.951 (1.308-2.909) & 0.001 & 1.165 (0.677-2.004) & 0.581 \\
\hline LVEF & 0.974 (0.959-0.990) & 0.002 & $0.983(0.962-1.004)$ & 0.120 \\
\hline $\mathrm{SCr}$ & $1.013(1.006-1.021)$ & 0.001 & $1.010(1.002-1.019)$ & 0.014 \\
\hline LDL-C & $1.078(0.916-1.269)$ & 0.366 & $1.028(0.852-1.239)$ & 0.774 \\
\hline FPG & $1.201(1.132-1.274)$ & $<0.001$ & $1.156(1.087-1.230)$ & $<0.001$ \\
\hline \multicolumn{5}{|l|}{ Clinical presentation } \\
\hline UAP & Reference & & Reference & \\
\hline NSTEMI & $0.677(0.416-1.102)$ & 0.117 & $0.467(0.275-0.792)$ & 0.005 \\
\hline STEMI & 1.098 (0.690-1.747) & 0.695 & $0.850(0.508-1.424)$ & 0.538 \\
\hline \multicolumn{5}{|l|}{ CAD severity } \\
\hline One-vessel disease & Reference & & Reference & \\
\hline Two-vessel disease & $1.756(0.809-3.810)$ & 0.154 & $1.230(0.549-2.755)$ & 0.615 \\
\hline LM/three-vessel disease & $3.541(1.740-7.205)$ & $<0.001$ & $1.823(0.858-3.873)$ & 0.118 \\
\hline Restenotic lesions & $2.290(1.658-3.163)$ & $<0.001$ & 1.667 (0.914-3.040) & 0.095 \\
\hline Lesions > 20 mm long & $1.984(1.461-2.695)$ & $<0.001$ & 1.566 (1.129-2.174) & 0.007 \\
\hline DCB use & $1.913(1.228-2.980)$ & 0.004 & 0.990 (0.571-1.715) & 0.970 \\
\hline Complete revascularization & $0.467(0.352-0.619)$ & $<0.001$ & $0.687(0.504-0.936)$ & 0.017 \\
\hline Insulin at discharge & $1.396(1.051-1.854)$ & 0.021 & $1.056(0.775-1.438)$ & 0.730 \\
\hline
\end{tabular}

Abbreviations as in Tables 1 and 2

tomography [41, 42]. Evidence indicates that epicardial adipose tissue directly affects coronary atherosclerosis [43]. The AIP was shown to be directly and independently associated with arterial stiffness in normotensive and never-treated hypertensive subjects [44]. Increased aortic stiffness often results in early wave reflection of the aortic pulse wave, which increases systolic blood pressure but decreases diastolic blood pressure, and these haemodynamic changes impair coronary perfusion, which can promote adverse cardiovascular events [36]. The AIP was demonstrated to be a marker for reduced coronary flow reserve [45], and the latter was positively associated with adverse cardiovascular events. Of note, the AIP comprises HDL-C and triglycerides in its formula. Low HDL-C and high triglyceride levels were shown to be associated with adverse cardiovascular events after ACS, independent of diabetic status [46, 47].

Glucose-lowering regimens including pioglitazone have been shown to be effective in reducing AIP values, thereby reducing cardiovascular risk [48, 49]. Moreover, moderate-to-vigorous physical activity, increased aerobic exercise time, decreased sedentary behaviour, and consequent high levels of cardiorespiratory fitness were reported to be inversely correlated with the AIP, which implies that a healthy lifestyle helps attenuate the risk for cardiovascular disease via AIP improvements [50-54]. As a result, the use of pioglitazone and early initiation of physical activity and aerobic exercise may be important to reduce future cardiovascular risk in T2DM patients with ACS undergoing PCI who have received first-line 
Table 4 Relationship between the incidence of the key secondary endpoint and the AIP expressed as a categorical variable

\begin{tabular}{|c|c|c|c|c|}
\hline Variables & $\begin{array}{l}\text { Univariate analysis } \\
\text { HR }(95 \% \mathrm{Cl})\end{array}$ & $P$-value & $\begin{array}{l}\text { Multivariate analysis } \\
\text { HR }(95 \% \mathrm{Cl})\end{array}$ & $P$-value \\
\hline \multicolumn{5}{|l|}{ AIP quartiles } \\
\hline Q1 & Reference & & Reference & \\
\hline Q2 & $1.380(0.555-3.432)$ & 0.488 & $0.985(0.362-2.679)$ & 0.976 \\
\hline Q3 & $2.020(0.865-4.720)$ & 0.104 & $1.822(0.734-4.524)$ & 0.196 \\
\hline Q4 & $2.477(1.085-5.659)$ & 0.031 & $2.571(1.027-6.440)$ & 0.044 \\
\hline Age & $1.042(1.013-1.072)$ & 0.004 & $1.016(0.984-1.048)$ & 0.331 \\
\hline BMI & $0.915(0.834-1.004)$ & 0.062 & $0.861(0.775-0.956)$ & 0.005 \\
\hline Hypertension & $1.333(0.725-2.450)$ & 0.354 & $1.303(0.664-2.558)$ & 0.442 \\
\hline Past PCl & $1.904(1.096-3.309)$ & 0.022 & $2.124(1.119-4.030)$ & 0.021 \\
\hline PAD & $5.804(3.402-9.902)$ & $<0.001$ & $3.068(1.677-5.613)$ & $<0.001$ \\
\hline Cardiac failure & 6.939 (3.993-12.061) & $<0.001$ & $1.870(0.774-4.517)$ & 0.164 \\
\hline LVEF & $0.924(0.902-0.946)$ & $<0.001$ & $0.947(0.912-0.983)$ & 0.004 \\
\hline $\mathrm{SCr}$ & $1.025(1.014-1.036)$ & $<0.001$ & $1.010(0.997-1.022)$ & 0.123 \\
\hline LDL-C & $1.064(0.774-1.463)$ & 0.702 & $1.102(0.731-1.661)$ & 0.644 \\
\hline Glycated haemoglobin & $1.090(0.882-1.347)$ & 0.425 & $1.243(0.974-1.587)$ & 0.081 \\
\hline \multicolumn{5}{|l|}{ Clinical presentation } \\
\hline UAP & Reference & & Reference & \\
\hline NSTEMI & $1.333(0.622-2.857)$ & 0.460 & $0.462(0.187-1.143)$ & 0.095 \\
\hline STEMI & $1.920(0.896-4.115)$ & 0.094 & $0.880(0.375-2.061)$ & 0.768 \\
\hline \multicolumn{5}{|l|}{ CAD severity } \\
\hline One-vessel disease & Reference & & Reference & \\
\hline Two-vessel disease & $0.201(0.037-1.096)$ & 0.064 & $0.060(0.009-0.399)$ & 0.004 \\
\hline LM/three-vessel disease & $1.910(0.689-5.296)$ & 0.214 & $0.476(0.142-1.593)$ & 0.228 \\
\hline Lesions > 20 mm long & $2.681(1.411-5.029)$ & 0.003 & $1.776(0.866-3.640)$ & 0.117 \\
\hline Complete revascularization & $0.403(0.232-0.700)$ & 0.001 & $0.677(0.346-1.321)$ & 0.253 \\
\hline ACEIs/ARBs at discharge & $2.933(1.596-5.391)$ & 0.001 & $1.659(0.825-3.335)$ & 0.155 \\
\hline
\end{tabular}

Abbreviations as in Tables 1 and 2

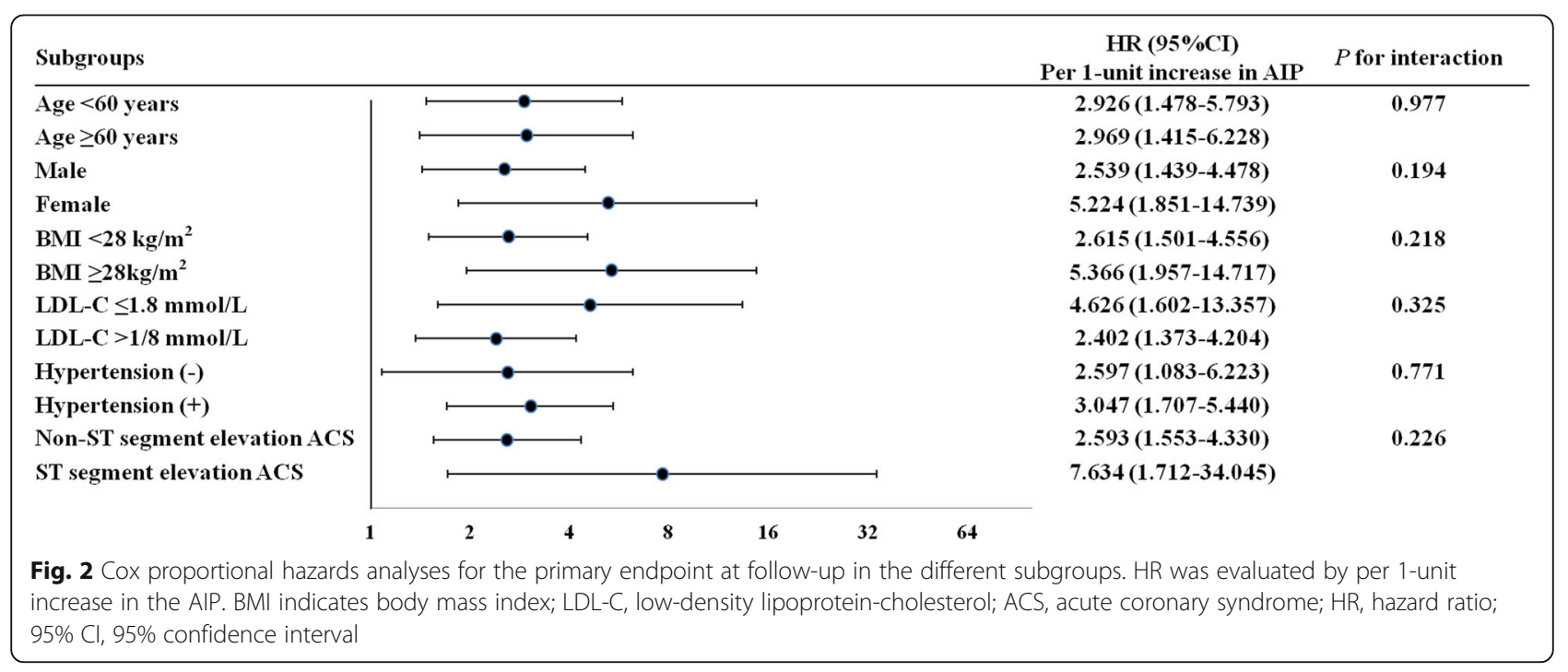


medication therapy but still have significantly increased AIP values.

\section{Study strength and limitations}

The present study demonstrated a significant association between the AIP and adverse cardiovascular outcomes in T2DM patients with ACS undergoing PCI. Even after adjustment for as many potential confounding variables as possible, there remained an independent association of the AIP with adverse cardiovascular outcomes. To our knowledge, this study is the first to report the prognostic impact of the AIP in T2DM and ACS patients who underwent PCI.

The present study has several limitations. First, this study was a retrospective analysis of a single-centre prospective registry. As in other observational studies, the effects of unmeasured and undetected confounding variables cannot be excluded in this study. Second, the baseline concentrations of triglycerides and HDL-C might be affected by the use of statins before admission and glycaemic control status. However, there were no significant differences among the AIP quartiles with respect to the use of statins before admission and glycated haemoglobin, which can consistently reflect glycaemic control status in diabetic patients. Third, unhealthy lifestyle and obstructive sleep apnea are associated with dyslipidemia and the development of cardiovascular disease. However, information on lifestyle (such as diet, exercise, etc.) and obstructive sleep apnea was not recorded and considered in this study. Fourth, follow-up data were obtained merely via telephone; however, the authenticity of adverse events was confirmed by reviewing corresponding medical records. Finally, all study patients were Chinese. While ethnic homogeneity might be considered an advantage, the findings derived from the present study may not be extrapolated to other ethnic groups without caution.

\section{Conclusions}

A higher AIP value on admission was independently and strongly associated with adverse cardiovascular events in T2DM patients with ACS undergoing PCI, suggesting that the AIP might have a potential role in the early risk stratification of such patients. Medical management optimization according to the AIP could result in a reduced risk of subsequent cardiovascular events.

\section{Abbreviations}

ACEIs/ARBs: Angiotensin-converting enzyme inhibitors/angiotensin ॥ receptor blockers; ACS: Acute coronary syndrome; AIP: Atherogenic index of plasma; BMI: Body mass index; CAD: Coronary artery disease; $\mathrm{Cl}$ : Confidence interval; FER (HDL): Cholesterol esterification rates in apoB-lipoproteindepleted plasma; FPG: Fasting plasma glucose; HDL-C: High-density lipoprotein-cholesterol; HR: Hazard ratio; LDL-C: Low-density lipoproteincholesterol; LVEF: Left ventricular ejection fraction; MI: Myocardial infarction; $\mathrm{PCl}$ : Percutaneous coronary intervention; T2DM: Type 2 diabetes mellitus

\section{Acknowledgements}

We thank Nature Research Editing Service (http://bit.ly/NRES-HS) for their linguistic assistance during the revision of this manuscript.

\section{Declarations}

The initial version submitted is present on a university repository website and can be accessed at https://www.researchsquare.com/article/rs-67794/v1. The initial version submitted is not published nor is it under publication elsewhere.

\section{Authors' contributions}

Xiaoteng Ma, Yan Sun, and Yujing Cheng contributed equally to this paper. All authors were involved in the conception and design of the study and in the collection, analysis, and interpretation of the data. All authors reviewed the final manuscript. All authors read and approved the final manuscript.

\section{Funding}

This work was supported by grants from the National Key Research and Development Program of China (2017YFC0908800), Beijing Municipal Administration of Hospitals' Ascent Plan (DFL20150601) and Mission Plan (SML20180601), Beijing Municipal Health Commission - "Project of Science and Technology Innovation Center" (PXM2019_026272_000006)

(PXM2019_026272_000005), and National Natural Science Foundation of China (81670391).

\section{Availability of data and materials}

The data, analytic methods, and study materials will not be made available to other researchers for purposes of reproducing the results or replicating the procedure.

\section{Ethics approval and consent to participate}

This study was approved by the institutional review board of Beijing Anzhen Hospital, Capital Medical University. Given the retrospective nature of this study, the requirement for informed consent was waived.

\section{Consent for publication}

Not applicable.

\section{Competing interests}

The authors declare that they have no competing interests.

Received: 13 October 2020 Accepted: 9 November 2020

Published online: 16 November 2020

\section{References}

1. Donahoe SM, Stewart GC, McCabe CH, Mohanavelu S, Murphy SA, Cannon $\mathrm{CP}$, Antman EM. Diabetes and mortality following acute coronary syndromes. Jama. 2007;298:765-75.

2. Kuhl J, Jörneskog G, Wemminger M, Bengtsson M, Lundman P, Kalani M. Long-term clinical outcome in patients with acute coronary syndrome and dysglycaemia. Cardiovasc Diabetol. 2015;14:120.

3. Koshizaka M, Lopes RD, Newby LK, Clare RM, Schulte PJ, Tricoci P, Mahaffey KW, Ogawa H, Moliterno DJ, Giugliano RP, et al. Obesity, diabetes, and acute coronary syndrome: differences between Asians and whites. Am J Med. 2017;130:1170-6.

4. Kaur R, Kaur M, Singh J. Endothelial dysfunction and platelet hyperactivity in type 2 diabetes mellitus: molecular insights and therapeutic strategies. Cardiovasc Diabetol. 2018;17:121.

5. Sardu C, Barbieri M, Balestrieri ML, Siniscalchi M, Paolisso P, Calabrò P, Minicucci F, Signoriello G, Portoghese M, Mone P, et al. Thrombus aspiration in hyperglycemic ST-elevation myocardial infarction (STEMI) patients: clinical outcomes at 1-year follow-up. Cardiovasc Diabetol. 2018;17:152.

6. Sasso FC, Pafundi PC, Marfella R, Calabrò P, Piscione F, Furbatto F, Esposito G, Galiero R, Gragnano F, Rinaldi L, et al. Adiponectin and insulin resistance are related to restenosis and overall new $\mathrm{PCl}$ in subjects with normal glucose tolerance: the prospective AIRE study. Cardiovasc Diabetol. 2019;18:24.

7. D'Onofrio N, Sardu C, Paolisso P, Minicucci F, Gragnano F, Ferraraccio F, Panarese I, Scisciola L, Mauro C, Rizzo MR, et al. MicroRNA-33 and SIRT1 influence the coronary thrombus burden in hyperglycemic STEMI patients. J Cell Physiol. 2020;235:1438-52. 
8. Giugliano RP, Cannon CP, Blazing MA, Nicolau JC, Corbalán R, Špinar J, Park JG, White JA, Bohula EA, Braunwald E. Benefit of adding Ezetimibe to statin therapy on cardiovascular outcomes and safety in patients with versus without diabetes mellitus: results from IMPROVE-IT (improved reduction of outcomes: Vytorin efficacy international trial). Circulation. 2018;137:1571-82.

9. Avogaro A, Bonora E, Consoli A, Del Prato S, Genovese S, Giorgino F. Glucoselowering therapy and cardiovascular outcomes in patients with type 2 diabetes mellitus and acute coronary syndrome. Diab Vasc Dis Res. 2019;16:399-414.

10. Ahn KT, Seong SW, Choi UL, Jin SA, Kim JH, Lee JH, Choi SW, Jeong MH, Chae SC, Kim YJ, et al. Comparison of 1-year clinical outcomes between prasugrel and ticagrelor versus clopidogrel in type 2 diabetes patients with acute myocardial infarction underwent successful percutaneous coronary intervention. Medicine (Baltimore). 2019:98:e14833.

11. Godoy LC, Lawler PR, Farkouh ME, Hersen B, Nicolau JC, Rao V. Urgent revascularization strategies in patients with diabetes mellitus and acute coronary syndrome. Can J Cardiol. 2019;35:993-1001.

12. Taskinen MR, Borén J. New insights into the pathophysiology of dyslipidemia in type 2 diabetes. Atherosclerosis. 2015;239:483-95.

13. Dobiásová M, Frohlich J. The new atherogenic plasma index reflects the triglyceride and HDL-cholesterol ratio, the lipoprotein particle size and the cholesterol esterification rate: changes during lipanor therapy. Vnitr Lek. 2000;46:152-6.

14. Dobiásová M, Frohlich J. The plasma parameter log (TG/HDL-C) as an atherogenic index: correlation with lipoprotein particle size and esterification rate in apoB-lipoprotein-depleted plasma (FER(HDL)). Clin Biochem. 2001;34:583-8

15. Dobiásová M, Raslová K, Rauchová H, Vohnout B, Ptácková K, Frohlich J. Atherogenic lipoprotein profile in families with and without history of early myocardial infarction. Physiol Res. 2001;50:1-8.

16. Dobiásová M, Urbanová Z, Samánek M. Relations between particle size of $\mathrm{HDL}$ and LDL lipoproteins and cholesterol esterification rate. Physiol Res. 2005:54:159-65.

17. Rašlová K, Dobiášová M, Hubáček JA, Bencová $D$, Siváková $D$, Danková $Z$, Franeková J, Jabor A, Gašparovič J, Vohnout B. Association of metabolic and genetic factors with cholesterol esterification rate in HDL plasma and atherogenic index of plasma in a 40 years old Slovak population. Physiol Res. 2011;60:785-95.

18. Dobiásová M, Frohlich J, Sedová M, Cheung MC, Brown BG. Cholesterol esterification and atherogenic index of plasma correlate with lipoprotein size and findings on coronary angiography. J Lipid Res. 2011;52:566-71.

19. Quispe R, Manalac RJ, Faridi KF, Blaha MJ, Toth PP, Kulkarni KR, Nasir K, Virani SS, Banach M, Blumenthal RS, et al. Relationship of the triglyceride to highdensity lipoprotein cholesterol (TG/HDL-C) ratio to the remainder of the lipid profile: the very large database of Lipids-4 (VLDL-4) study. Atherosclerosis. 2015;242:243-50.

20. Frohlich J, Dobiásová M. Fractional esterification rate of cholesterol and ratio of triglycerides to $\mathrm{HDL}$-cholesterol are powerful predictors of positive findings on coronary angiography. Clin Chem. 2003;49:1873-80.

21. Onat A, Can G, Kaya H, Hergenç G. "Atherogenic index of plasma" (log10 triglyceride/high-density lipoprotein-cholesterol) predicts high blood pressure, diabetes, and vascular events. J Clin Lipidol. 2010;4:89-98.

22. Shanker J, Kakkar W. Contribution of classical and emerging risk factors to coronary artery disease in Asian Indians. Int J Cardiol. 2016:214:97-106.

23. Edwards MK, Blaha MJ, Loprinzi PD. Atherogenic index of plasma and triglyceride/high-density lipoprotein cholesterol ratio predict mortality risk better than individual cholesterol risk factors, among an older adult population. Mayo Clin Proc. 2017;92:680-1.

24. Bendzala M, Sabaka P, Caprnda M, Komornikova A, Bisahova M, Baneszova $R$, Petrovic D, Prosecky R, Rodrigo L, Kruzliak P, Dukat A. Atherogenic index of plasma is positively associated with the risk of all-cause death in elderly women : a 10-year follow-up. Wien Klin Wochenschr. 2017;129:793-8.

25. Lee MJ, Park JT, Han SH, Kim YL, Kim YS, Yang CW, Kim NH, Kang SW, Kim $\mathrm{HJ}$, Yoo TH. The atherogenic index of plasma and the risk of mortality in incident dialysis patients: results from a nationwide prospective cohort in Korea. PLoS One. 2017;12:e0177499.

26. Cai G, Shi G, Xue S, Lu W. The atherogenic index of plasma is a strong and independent predictor for coronary artery disease in the Chinese Han population. Medicine (Baltimore). 2017;96:e8058.

27. Wu TT, Gao Y, Zheng YY, Ma YT, Xie X. Atherogenic index of plasma (AIP): a novel predictive indicator for the coronary artery disease in postmenopausal women. Lipids Health Dis. 2018;17:197.
28. Cai G, Liu W, Lv S, Wang X, Guo Y, Yan Z, Du Y, Zhou Y. Gender-specific associations between atherogenic index of plasma and the presence and severity of acute coronary syndrome in very young adults: a hospital-based observational study. Lipids Health Dis. 2019;18:99.

29. Guo Q, Zhou S, Feng X, Yang J, Qiao J, Zhao Y, Shi D, Zhou Y. The sensibility of the new blood lipid indicator--atherogenic index of plasma (AIP) in menopausal women with coronary artery disease. Lipids Health Dis. 2020;19:27.

30. Qin Z, Zhou K, Li Y, Cheng W, Wang Z, Wang J, Gao F, Yang L, Xu Y, Wu Y, et al. The atherogenic index of plasma plays an important role in predicting the prognosis of type 2 diabetic subjects undergoing percutaneous coronary intervention: results from an observational cohort study in China. Cardiovasc Diabetol. 2020;19:23.

31. Nam JS, Kim MK, Nam JY, Park K, Kang S, Ahn CW, Park JS. Association between atherogenic index of plasma and coronary artery calcification progression in Korean adults. Lipids Health Dis. 2020;19:157.

32. Ma X, Dong L, Shao Q, Cheng Y, Lv S, Sun Y, Shen H, Wang Z, Zhou Y, Liu $X$. Triglyceride glucose index for predicting cardiovascular outcomes after percutaneous coronary intervention in patients with type 2 diabetes mellitus and acute coronary syndrome. Cardiovasc Diabetol. 2020;19:31.

33. Amsterdam EA, Wenger NK, Brindis RG, Casey DE Jr, Ganiats TG, Holmes DR Jr, Jaffe AS, Jneid H, Kelly RF, Kontos MC, et al. AHA/ACC guideline for the management of patients with non-ST-elevation acute coronary syndromes: executive summary: a report of the American College of Cardiology/ American Heart Association task force on practice guidelines. Circulation. 2014;2014(130):2354-94

34. O'Gara PT, Kushner FG, Ascheim DD, Casey DE Jr, Chung MK, de Lemos JA, Ettinger SM, Fang JC, Fesmire FM, Franklin BA, et al. ACCF/AHA guideline for the management of ST-elevation myocardial infarction: a report of the American College of Cardiology Foundation/American Heart Association task force on practice guidelines. Circulation. 2013;2013(127):e362-425.

35. American Diabetes Association. Diagnosis and classification of diabetes mellitus. Diabetes Care. 2014;37( Suppl):S81-90.

36. Ma X, Dong L, Shao Q, Zhou Z, Tian J, Ma Y, Yang J, Lv S, Cheng Y, Shen $H_{\text {, }}$ et al. Predictive performance of aortic arch calcification for clinical outcomes in patients with acute coronary syndrome that undergo percutaneous coronary intervention: a prospective clinical study. Medicine (Baltimore). 2019;98:e18187.

37. Gragnano F, Calabrò P. Role of dual lipid-lowering therapy in coronary atherosclerosis regression: evidence from recent studies. Atherosclerosis. 2018;269:219-28.

38. Dobiášová M. Atherogenic impact of lecithin-cholesterol acyltransferase and its relation to cholesterol esterification rate in $\mathrm{HDL}(\mathrm{FER}(\mathrm{HDL}))$ and AIP [log(TG/HDL-C)] biomarkers: the butterfly effect? Physiol Res. 2017;66:193-203.

39. Amrita J, Mahajan M, Bhanwer AJ, Mohan G. Oxidative stress: an effective prognostic tool for an early detection of cardiovascular disease in menopausal women. Biochem Res Int. 2016;2016:6157605.

40. Haberland ME, Fong D, Cheng L. Malondialdehyde, modified lipoproteins, and atherosclerosis. Eur Heart J. 1990;11(Suppl E):100-4.

41. Erdur MF, Tonbul HZ, Ozbiner H, Ozcicek A, Ozcicek F, Akbas EM, Ozbek O, Hamur $\mathrm{H}$, Turkmen $\mathrm{K}$. The relationship between atherogenic index of plasma and epicardial adipose tissue in hemodialysis and peritoneal dialysis patients. Ren Fail. 2013;35:1193-8.

42. Akbas EM, Hamur H, Demirtas L, Bakirci EM, Ozcicek A, Ozcicek F, Kuyrukluyildiz U, Turkmen K. Predictors of epicardial adipose tissue in patients with type 2 diabetes mellitus. Diabetol Metab Syndr. 2014;6:55.

43. Madonna R, Massaro M, Scoditti E, Pescetelli I, De Caterina R. The epicardial adipose tissue and the coronary arteries: dangerous liaisons. Cardiovasc Res. 2019;115:1013-25

44. Choudhary MK, Eräranta A, Koskela J, Tikkakoski AJ, Nevalainen PI, Kähönen M, Mustonen J, Pörsti I. Atherogenic index of plasma is related to arterial stiffness but not to blood pressure in normotensive and never-treated hypertensive subjects. Blood Press. 2019;28:157-67.

45. Kul Ş, Çalışkan Z, Güvenç TS, Güvenç R, Çalışkan M. Plasma lipids in patients with inflammatory bowel disease : observations on the associations between lipid indices and coronary flow reserve. Wien Klin Wochenschr. 2020;132:283-94.

46. Schwartz GG, Abt M, Bao W, DeMicco D, Kallend D, Miller M, Mundl H, Olsson AG. Fasting triglycerides predict recurrent ischemic events in patients with acute coronary syndrome treated with statins. J Am Coll Cardiol. 2015;65:2267-75. 
47. Nakazawa M, Arashi H, Yamaguchi J, Ogawa H, Hagiwara N. Lower levels of high-density lipoprotein cholesterol are associated with increased cardiovascular events in patients with acute coronary syndrome. Atherosclerosis. 2020;303:21-8.

48. Rodríguez A, Reviriego J, Karamanos V, del Cañizo FJ, Vlachogiannis N, Drossinos $V$. Management of cardiovascular risk factors with pioglitazone combination therapies in type 2 diabetes: an observational cohort study. Cardiovasc Diabetol. 2011;10:18.

49. Tan MH, Johns D, Glazer NB. Pioglitazone reduces atherogenic index of plasma in patients with type 2 diabetes. Clin Chem. 2004;50:1184-8.

50. Edwards MK, Blaha MJ, Loprinzi PD. Influence of sedentary behavior, physical activity, and cardiorespiratory fitness on the atherogenic index of plasma. J Clin Lipidol. 2017;11:119-25.

51. Shen S, Lu Y, Dang Y, Qi H, Shen Z, Wu L, Li F, Yang C, Qiang D, Yang Y, et al. Effect of aerobic exercise on the atherogenic index of plasma in middle-aged Chinese men with various body weights. Int I Cardiol. 2017; 230:1-5.

52. Shen S, Qi H, He X, Lu Y, Yang C, Li F, Wang L, Qiang D, Shui K, Zhou L, et al. Aerobic exercise for a duration of 90 min or longer per week may reduce the Atherogenic index of plasma. Sci Rep. 2018;8:1730.

53. Edwards M, Loprinzi P. The dose-response association between reported moderate to vigorous intensity physical activity and Atherogenic index of plasma: NHANES, 1999-2006. J Phys Act Health. 2019;16:368-70.

54. Reyes-Ferrada W, Solis-Urra P, Plaza-Díaz J, Sadarangani KP, de Moraes Ferrari GL, Rodríguez-Rodríguez F, Cristi-Montero C. Cardiorespiratory fitness, physical activity, sedentary time and its association with the Atherogenic index of plasma in Chilean adults: influence of the waist circumference to height ratio. Nutrients. 2020;12.

\section{Publisher's Note}

Springer Nature remains neutral with regard to jurisdictional claims in published maps and institutional affiliations.

Ready to submit your research? Choose BMC and benefit from:

- fast, convenient online submission

- thorough peer review by experienced researchers in your field

- rapid publication on acceptance

- support for research data, including large and complex data types

- gold Open Access which fosters wider collaboration and increased citations

- maximum visibility for your research: over $100 \mathrm{M}$ website views per year

At $\mathrm{BMC}$, research is always in progress.

Learn more biomedcentral.com/submissions 